IP Periodica Polytechnica

Transportation Engineering

46(4), pp. 201-206, 2018

https://doi.org/10.3311/PPtr.10939

Creative Commons Attribution (i)

RESEARCH ARTICLE

\section{Evaluation of Automated Enforcement Program in Amman}

\author{
Hana Naghawi ${ }^{1 *}$, Bushra Al Qatawneh ${ }^{1}$, Rabab Al Louzi ${ }^{1}$
}

Received 24 April 2017; accepted 09 November 2017

\begin{abstract}
This study aims, in a first attempt, to evaluate the effectiveness of using the Automated Enforcement Program (AEP) to improve traffic safety in Amman, Jordan. The evaluation of the program on crashes and violations was examined based on a "before-and-after" study using the paired t-test at 95 percent confidence level. Twenty one locations including signalized intersections monitored by red light cameras and arterial roads monitored by excessive speed cameras were selected. Nine locations were used to study the effectiveness of the program on violations, and twelve locations were used to determine the effectiveness of the program on frequency and severity of crashes. Data on number and severity of crashes were taken from Jordan Traffic Institution. Among the general findings, it was found that the AEP was generally associated with positive impact on crashes. Crash frequency was significantly reduced by up to $63 \%$. Crash severities were reduced by up to $62.5 \%$. Also, traffic violations were significantly reduced by up to $66 \%$. Finally, drivers'opinion and attitude on the program was also analyzed using a questionnaire survey. The questionnaire survey revealed that $35.5 \%$ of drivers are unaware of AEP in Amman, 63.9\% of drivers don't know the camera locations, most drivers knew about excessive speed and red light running penalties, most drivers reduce their speed at camera locations, $44.4 \%$ of drivers think that the program satisfies its objective in improving traffic safety and 52\% of drivers encourage increasing the number of camera devices in Amman.
\end{abstract}

\section{Keywords}

Automated Enforcement Program, Red Light Camera, Excessive Speed Camera, Public Opinion, Road Safety

${ }^{1}$ Civil Engineering Department, University of Jordan, Amman 11942, Jordan

*Corresponding author, e-mail: h.naghawi@ju.edu.jo

\section{Introduction}

Worldwide, aggressive driving has become a serious problem on roadways. This results in enormous number of crashes every day. The National Highway Traffic Safety Administration (NHTSA, 2015) estimates that 94\% of traffic crashes and almost $66 \%$ of traffic fatalities are caused by dangerous driving activities or driver's errors. Excessive speeding and red light running are among the most common illegal dangerous driving activities (Dangerous Roads Organization, 2013).

Excessive speeding (ES) is defined as driving too fast for the prevailing conditions or exceeding the speed limit. Red light running (RLR) can be defined as to pass through an intersection when traffic light has turned red. Traditionally, the enforcement of this type of traffic violations involve policeman monitoring the road or the signalized intersection for violators. This type of manual enforcement can be difficult and hazardous at some locations. Automated Enforcement Program (AEP) addresses this problem. AEP is becoming increasingly popular in many countries to improve traffic safety by controlling drivers' behaviour. It can briefly be described as the use of image capture technology to monitor traffic twenty four hours a day to enforce traffic laws. It can be done using mobile or fixed cameras. Mobile cameras are accompanied by enforcement officer and maybe moved among various locations, while fixed cameras monitor speeds at specific locations and are unaccompanied by enforcement officers.

The effectiveness of AEP in improving traffic safety was evaluated by many researchers. A study by Al Jassar and Ali (2004) evaluated the AEP in Kuwait. It included 93 camera locations $39 \mathrm{ES}$ cameras and 54 RLR cameras, in addition to 8 mobile cameras. The results indicated that fatalities were reduced by $15 \%$ after implementing the AEP. Some researchers evaluated the effectiveness of ES cameras in reducing speeding violations and traffic crashes (Decina et al., 2007; Wilson et al., 2010; Allsop, 2010). In Barcelona, Perez et al. (2007) conducted a study to evaluate the ES cameras for Barcelona's ring road in reducing traffic crashes. The study revealed that crashes were reduced by $27 \%$ after the installation of the ES cameras. Gains et al. (2004), evaluated the effectiveness of ES cameras in the United Kingdome, they 
found that the deployment of speed cameras resulted in $40 \%$ reduction in fatalities and serious injuries, 30\% reduction in personal injury crashes, and a $35 \%$ reduction in the number of pedestrians killed or seriously injured. Another study in the United Kingdome by Mountain (2004) evaluated the ES cameras. He found that there was a reduction of about $25 \%$ in injury crashes up to $500 \mathrm{~m}$ from camera location. Wilson et al. (2010) conducted a systematic review to evaluate the speed camera effectiveness in Europe and Australia. They reported (14-65) \% reduction in the percentage of vehicles exceeding the posted speed limit, (8-49) \% reduction in speed associated crashes, (8-50) \% reduction in injury crashes and (11-44) $\%$ reduction in fatal crashes. In the USA, $\mathrm{Hu}$ and $\mathrm{McCartt}$ (2015) evaluated the long term effect of the automated speed enforcement program at residential streets with speed limit 35 mph or less and school zones. It was found that the mean speed was reduced by $10 \%$ and fatal crashes were reduced by $39 \%$. Researchers at Weill Cornell Medical College in Doha studied the efficiency of using speed camera systems. The study indicated that the mean vehicular injury death rate per 100,000 was decreased from $19.9 \pm 4.1$ before camera installation to $14.7 \pm 1.5$ after camera installation (ITS International, 2012).

Other researchers have identified the effect of RLR camera enforcement on crash reduction benefits. Ruby and Hobeika (2003) assessed the RLR camera enforcement program in Fairfax, Virginia. Ten cameras were installed at high commuter traffic intersections. It was found that the violation rates were reduced by $36 \%$ during the first three months of installation and up to $69 \%$ after six month of camera installation. Retting and Kyrychenko (2002) evaluated the use of RLR cameras at eleven signalized and unsignalized intersections in Oxnard, California. The study revealed a reduction of $7 \%$ in all crashes and a reduction of $29 \%$ in all injuries. Walden (2011) evaluated the impact of RLR cameras on crash frequency in Texas, USA. He investigated 275 signalized intersections from around the state. He found that the RLR camera reduced the total number of crashes by $28 \%$. Maccubbin et al. (2001) reported reduction in violation rates ranging from $20 \%$ to $87 \%$ for jurisdictions in the USA. These findings were similar to the findings in Singapore and Canada (Mullen, 2001; Lum and Wong, 2003). On the other hand some studies showed that cameras are not without limitations and possible problems such as increased rear end crashes and spillovers (Chinnock, 2005).

In Jordan, there has been no research conducted to evaluate AEP on crashes and violations. This study aims to evaluate the effectiveness of using the AEP to improve traffic safety at arterial roads and signalized intersections in Amman, Jordan. The effect of the AEP on crash frequencies, severities and violations were examined. Drivers' opinion and attitude on AEP was also examined using a questionnaire survey. Generally, this study proved the success of automated enforcement program in Amman.

\section{Program Description and Site Selection}

Amman is the capital and most populated city in Jordan, with a geographic area of 1,689 square kilometers and a population of more than nine million in 2015 (DOS, 2016). According to Jordan Traffic Institution (JTI, 2016) approximately every 5 minutes a traffic crash occurs and every 14 hours a person gets killed in a traffic crash.

Table 1 shows crashes, fatalities and injuries between 2006 and 2015. It can be seen that traffic crashes in Jordan has increased from 98,055 in 2006 to 111,057 in 2015; the resulting casualties (fatalities and injuries) have improved leading to a reduction in severity rates (casualty/crash) from 0.19 in 2006 to 0.15 in 2015 . Also, the fatality index (fatalities/causalities) has decreased from 0.048 to 0.036 during the same period of time. Jadaan et al. (2013) developed road fatality prediction model under Jordanian conditions and based on aggregated data, they predicted that by 2020 , the number of road crash fatalities will reach 1054 . This is $73.35 \%$ higher than fatalities in 2015 . This indicates relatively low level of traffic safety in Jordan.

Table 1 Crash Frequencies Fatalities and Injuries between 2006 and 2015

\begin{tabular}{lccccc}
\hline Year & Crashes & Fatalities & Injuries & $\begin{array}{c}\text { Severity } \\
\text { Rate }\end{array}$ & $\begin{array}{c}\text { Fatality } \\
\text { Index }\end{array}$ \\
\hline $\mathbf{2 0 0 6}$ & 98055 & 899 & 18019 & 0.193 & 0.048 \\
$\mathbf{2 0 0 7}$ & 110630 & 992 & 17969 & 0.171 & 0.052 \\
$\mathbf{2 0 0 8}$ & 101066 & 740 & 13913 & 0.145 & 0.051 \\
$\mathbf{2 0 0 9}$ & 122793 & 676 & 15662 & 0.133 & 0.041 \\
$\mathbf{2 0 1 0}$ & 140014 & 670 & 17403 & 0.129 & 0.037 \\
$\mathbf{2 0 1 1}$ & 142588 & 694 & 18122 & 0.132 & 0.037 \\
$\mathbf{2 0 1 2}$ & 112817 & 816 & 17143 & 0.159 & 0.045 \\
$\mathbf{2 0 1 3}$ & 107864 & 768 & 15954 & 0.155 & 0.046 \\
$\mathbf{2 0 1 4}$ & 102441 & 688 & 14790 & 0.151 & 0.044 \\
$\mathbf{2 0 1 5}$ & 111057 & 608 & 16139 & 0.151 & 0.036 \\
\hline
\end{tabular}

Source: JTI, 2016

Excessive speeding and red light running are among the leading causes of crashes in Jordan. Traditional law enforcement alone is not enough to deter violations. Central traffic department at Greater Amman Municipality (GAM) sought to develop AEP that would optimize safety at most dangerous intersections and major arterial roads in Amman. The AEP has gradually expanded since its initiation. Initially there were five cameras installed in December 2004. As of December 2007 there were additional nineteen cameras installed. Finally, twenty one cameras were added in January 2014 to make the total number of cameras forty five cameras. Unfortunately, crash frequency, severity, speed and violation data were not recorded before the year 2011 which will only enable the latest twenty one camera locations to be studied. For the purpose of this study, the effectiveness of RLR cameras on frequency and severity of crashes was examined at five signalized intersections and the effectiveness of ES cameras on frequency and severity 
of crashes was examined at seven locations on arterial roads with (60-70) km/hr speed limit, as summarized in Table 2. The effectiveness of RLR cameras on number of violations was examined at different five signalized intersections and the effectiveness of ES cameras on number of violations was also examined at different four locations on arterial roads with (6070 ) $\mathrm{km} / \mathrm{hr}$ speed limit, as summarized in Table 3 . This resulted in studying all camera locations installed in the year 2014 .

Table 2 Camera locations used for Evaluating AEP on Crash Frequency and Severity

\begin{tabular}{lcl}
\hline Location ID & Camera Code & \multicolumn{1}{c}{ Intersection / Street } \\
\hline $\mathbf{1}$ & RLR Camera Location on Intersections \\
$\mathbf{2}$ & 1000 & Al-Ersal \\
$\mathbf{3}$ & 1001 & Abu Baker \\
$\mathbf{4}$ & 1002 & Queen Zain Al-Sharaf -1 \\
$\mathbf{5}$ & 1003 & Queen Zain Al-Sharaf -2 \\
\hline & 1004 & Al-Maslakh \\
\hline $\mathbf{6}$ & ES Camera Location on Arterial Roads \\
$\mathbf{7}$ & 1100 & Al-Hijaz \\
$\mathbf{8}$ & 1101 & Abu Nusair \\
$\mathbf{9}$ & 1102 & Al-Urdon \\
$\mathbf{1 0}$ & 1103 & Al-Aqsa \\
$\mathbf{1 1}$ & 1104 & Al-Shahid \\
$\mathbf{1 2}$ & 1105 & Army-1 \\
\hline $\mathbf{5 0 u r}$ & 1106 & Prince Hashim bin Al-Hussein \\
\hline
\end{tabular}

Source: GAM, 2017

Table 3 Camera locations used for Evaluating AEP on Violations

\begin{tabular}{lcl}
\hline Location ID & Camera Code & \multicolumn{1}{c}{ Intersection / Street } \\
\hline $\mathbf{1 3}$ & RLR Camera Location on Intersections \\
$\mathbf{1 4}$ & 103 & Crown \\
$\mathbf{1 5}$ & 201 & Commodore \\
$\mathbf{1 6}$ & 401 & Al-Kindi \\
$\mathbf{1 7}$ & 501 & Al-Dokhan \\
\hline & 801 & Al-Thalathin \\
\hline $\mathbf{1 8}$ & ES Camera Location on Arterial Roads \\
$\mathbf{1 9}$ & 901 & Army-2 \\
$\mathbf{2 0}$ & 904 & Al-Hizam Ring Road \\
$\mathbf{2 1}$ & 911 & Al-Istiqlal \\
\hline
\end{tabular}

Source: GAM, 2017

\section{Data Collection}

Data were obtained from three sources; Greater Amman Municipality, Jordan Traffic Institute, and a questionnaire survey. Data obtained from GAM included location of roads monitored by ES cameras, signalized intersections monitored by RLR cameras and number of violations that were registered by both types of cameras. Number and severity of crashes were taken from JTI. Drivers' attitude and opinion was analyzed using a questionnaire survey.

\section{Program Evaluation}

Evaluation of AEP in Amman was based on a "before-andafter" study. January 2011 to January 2014 represent the before period and January 2014 to January 2017 represent the after period. The appropriate statistical test for performing this type of comparison is the paired t-test. The paired t-test was performed at 95 percent confidence level to determine if there were any differences in crash frequency, crash severity or violation numbers before and after the implementation of the AEP.

To accomplish this, the following null and alternative hypotheses were used for each comparison:

$H_{0}$ : the differences in crash frequency, crash severity or violation numbers before and after the implementation of the AEP are equally.

$H_{1}$ : the differences in crash frequency, crash severity or violation numbers before and after the implementation of the AEP are different.

\subsection{AEP Effect on Crash Frequency}

Locations 1 through 12 were used to study the effect of implementing the AEP on crash frequency. Table 4 summarizes the crash frequency mean value before and after the AEP implementation. The table also shows the percent change in crash frequency before and after the AEP implementation. The statistically significant results are highlighted in the table and shown in italic font.

Table 4 Crash Frequencies Before and After AEP Implementation

\begin{tabular}{llllll}
\hline $\begin{array}{l}\text { Location } \\
\text { ID }\end{array}$ & $\begin{array}{l}\text { Crashes } \\
\text { Before }\end{array}$ & $\begin{array}{l}\text { Crashes } \\
\text { After }\end{array}$ & $\begin{array}{l}\text { \% } \\
\text { Change }\end{array}$ & P-value & $\begin{array}{l}\text { Hypothesis } \\
\text { Test Result }\end{array}$ \\
\hline $\mathbf{1}$ & 89 & 91 & 2.24 & 0.557 & Fail to Reject \\
$\mathbf{2}$ & 31 & 42 & 35.48 & 0.006 & Reject \\
$\mathbf{3}$ & 29 & 12 & -58.62 & 0.000 & Reject \\
$\mathbf{4}$ & 29 & 12 & -58.62 & 0.000 & Reject \\
$\mathbf{5}$ & 102 & 38 & -62.75 & 0.000 & Reject \\
\hline & & & $\mathbf{E S}$ & & \\
\hline $\mathbf{6}$ & 95 & 50 & -47.37 & 0.002 & Reject \\
$\mathbf{7}$ & 83 & 73 & -12.05 & 0.392 & Fail to Reject \\
$\mathbf{8}$ & 174 & 79 & -54.59 & 0.023 & Reject \\
$\mathbf{9}$ & 47 & 31 & -34.04 & 0.049 & Reject \\
$\mathbf{1 0}$ & 78 & 63 & -19.23 & 0.015 & Reject \\
$\mathbf{1 1}$ & 27 & 22 & -18.51 & 0.041 & Reject \\
$\mathbf{1 2}$ & 61 & 82 & 34.42 & 0.086 & Fail to Reject \\
\hline
\end{tabular}

It can be seen that crash frequency was significantly reduced at eight camera locations. It was significantly reduced at three RLR camera locations by almost (59-63) \% and by almost (1955) $\%$ at five ES camera locations. It can also be seen that crash frequency was significantly increased by $35 \%$ at one RLR camera location. This might be explained by the high speed 
of the two intersecting roads at that intersection, Al-Ersal intersection, which might lead to the increased probability of rear-end crashes.

\subsection{AEP Effect on Crash Severity}

The effect of implementing the AEP on crash severity was also tested on locations 1 through 12 . Table 5 summarizes crash severity mean value before and after the AEP implementation. The table also shows the percent change in crash severity before and after the AEP implementation and the statistical significance of the results.

Table 5 Crash Severity Before and After AEP Implementation

\begin{tabular}{llllll}
\hline $\begin{array}{l}\text { Location } \\
\text { ID }\end{array}$ & $\begin{array}{l}\text { Injury/ } \\
\text { Fatally } \\
\text { Before }\end{array}$ & $\begin{array}{l}\text { Injury/ } \\
\text { Fatally } \\
\text { After }\end{array}$ & $\begin{array}{l}\text { \% } \\
\text { Change }\end{array}$ & P-value & $\begin{array}{l}\text { Hypothesis } \\
\text { Test Result }\end{array}$ \\
\hline $\mathbf{1}$ & 10 & 10 & 0 & 0.885 & Fail to Reject \\
$\mathbf{2}$ & 4 & 3 & -25 & 0.049 & Reject \\
$\mathbf{3}$ & 1 & 1 & 0 & 0.423 & Fail to Reject \\
$\mathbf{4}$ & 1 & 1 & 0 & 0.423 & Fail to Reject \\
$\mathbf{5}$ & 15 & 9 & -40 & 0.035 & Reject \\
\hline $\mathbf{6}$ & & & $\mathbf{E S}$ & & \\
\hline $\mathbf{7}$ & 9 & 4 & -55.55 & 0.049 & Reject \\
$\mathbf{8}$ & 11 & 6 & -45.45 & 0.034 & Reject \\
$\mathbf{9}$ & 16 & 6 & -62.5 & 0.049 & Reject \\
\hline $\mathbf{1 0}$ & 4 & 4 & 0 & 0.910 & Fail to Reject \\
\hline & 8 & 7 & -12.5 & 0.822 & Fail to Reject \\
\hline & 2 & 2 & 0 & 0.885 & Fail to Reject \\
\hline & & 5 & -16.67 & 0.478 & Fail to Reject \\
\hline
\end{tabular}

Table 5 shows that crash severities were significantly reduced at only five camera locations. Crash severities were significantly reduced by up to $40 \%$ at two RLR camera locations and by up to $62.5 \%$ at three ES camera locations. The severities on the remaining AEP sites were not changed or were reduced with no statistical significance.

\subsection{AEP Effect on Violations}

Locations 13 through 21 were used to study the effect of implementing the AEP on violations. Table 6 summarizes violation mean values before and after the AEP implementation. The table shows the percent change in violations before and after the AEP implementation. The statistically significant results are also highlighted in the table and shown in italic font.

It can be concluded that traffic violations were significantly reduced at six locations. Violations were significantly reduced by (40-60) \% at two RLR camera locations and by (20-66) \% at all ES camera locations. The violations on the remaining AEP sites were reduced but with no statistical significance.
Table 6 Violations Before and After AEP Implementation

\begin{tabular}{llllll}
\hline $\begin{array}{l}\text { Location } \\
\text { ID }\end{array}$ & $\begin{array}{l}\text { Violation } \\
\text { Before }\end{array}$ & $\begin{array}{l}\text { Violation } \\
\text { After }\end{array}$ & $\begin{array}{l}\text { \% } \\
\text { Change }\end{array}$ & P-value & $\begin{array}{l}\text { Hypothesis } \\
\text { Test Result }\end{array}$ \\
\hline $\mathbf{1 3}$ & 5475 & 3285 & -40 & 0.003 & Reject \\
$\mathbf{1 4}$ & 21900 & 26645 & 21.7 & 0.249 & Fail to Reject \\
$\mathbf{1 5}$ & 32120 & 27740 & -13.6 & 0.327 & Fail to Reject \\
$\mathbf{1 6}$ & 14600 & 5840 & -60 & 0.043 & Reject \\
$\mathbf{1 7}$ & 8395 & 7300 & -13.1 & 0.413 & Fail to Reject \\
\hline & & & ES & & \\
\hline $\mathbf{1 8}$ & 27375 & 18980 & -30.7 & 0.013 & Reject \\
$\mathbf{1 9}$ & 21270 & 13870 & -34.5 & 0.007 & Reject \\
$\mathbf{2 0}$ & 13870 & 4745 & -65.8 & 0.001 & Reject \\
$\mathbf{2 1}$ & 73730 & 59130 & -19.8 & 0.019 & Reject \\
\hline
\end{tabular}

\section{Drivers Opinion and Attitude}

To assess drivers' opinion and attitude towards the AEP, a questionnaire survey was conducted in November 2016. A sample size of 385 was calculated using an online calculator assuming a confidence level of $95 \%$ with a marginal error of $5 \%, 301$ drivers responded. The questionnaire was distributed to drivers having different driving license types. The survey was divided into two parts. Part one of the survey contained three demographic questions about gender, age and educational level and one question was about the driver's driving license type. $67.6 \%$ of the respondents were male drivers, $83.4 \%$ were younger than 35 years old, $30.4 \%$ had higher educational level and the remaining had high school or diploma educational level, $88.4 \%$ had a private driving license while $7.5 \%$ had a public driving license and $4.1 \%$ had other types of driving license.

Part two of the survey contained a total of fifteen AEP related questions. Four of them were about driver's awareness of the AEP, two questions were about the AEP penalties, four questions were about the effectiveness of the AEP on driving behaviour, one question was about the perceived effects of AEP on roadway safety, two question were about the level of support and acceptance of AEP, and two question were if drivers favour AEP than policeman. Table 7 shows a list of the AEP related survey questions showing the percentages of the probable answer.

When drivers were asked about the AEP awareness, it was found that $35.5 \%$ of drivers are unaware of AEP in Amman and $63.9 \%$ of them don't know the camera locations in Amman, almost half of them think that drivers should not be informed about camera locations. Finally, $41.8 \%$ of drivers understand the concept behind the AEP.

Also, when drivers were asked about the AEP penalties, it was found that most drivers knew about ES and RLR penalties.

With regard to the effectiveness of the program on driving behaviour, $85.4 \%$ of drivers reduce their speed at camera 


\begin{tabular}{|c|c|c|c|c|}
\hline & \multirow{2}{*}{ Question } & \multicolumn{3}{|c|}{ Response (\%) } \\
\hline & & Yes & No & Maybe \\
\hline \multirow{4}{*}{ AEP Awareness } & 1. Do you know about the AEP in Amman? & 35.5 & 49.3 & 15.2 \\
\hline & 2. Do you know camera locations in Amman? & 11.8 & 63.9 & 24.3 \\
\hline & 3. Do you think that drivers should not be informed about camera location? & 42.4 & 42.7 & 14.9 \\
\hline & 4. Do you know how AEP works? & 41.8 & 38.5 & 19.7 \\
\hline \multirow{2}{*}{ AEP Penalty } & 5. Do you know the penalty of exceeding speed limits? & 59.3 & 20.5 & 20.2 \\
\hline & 6. Do you know the penalty of red right running? & 70.7 & 19.1 & 10.2 \\
\hline \multirow{4}{*}{$\begin{array}{l}\text { AEP Effect on } \\
\text { Driving Behaviour }\end{array}$} & 7. Do you reduce your speed at camera location? & 85.4 & 5.4 & 9.2 \\
\hline & 8. Do the presences of cameras affect your behavior at similar locations with no cameras? & 56.1 & 21.3 & 22.6 \\
\hline & 9. Do the presences of camera deter the drivers from breaking traffic laws? & 72.1 & 9.4 & 18.5 \\
\hline & 10. Do you note that the behavior of other drivers is affected by the presence of camera? & 76.9 & 12.6 & 10.5 \\
\hline $\begin{array}{l}\text { AEP Effect on } \\
\text { Safety }\end{array}$ & 11. Where you involved in a crash at the camera location? & 12.8 & 85.2 & 2.0 \\
\hline \multirow{2}{*}{ AEP Acceptance } & 12. Do you approve the use of AEP to enhance safety? & 44.4 & 25.4 & 30.2 \\
\hline & 13. Do you encourage the idea of increasing the number of camera devices in Amman? & 52 & 34.4 & 13.6 \\
\hline \multirow{2}{*}{$\begin{array}{l}\text { AEP than } \\
\text { Policeman }\end{array}$} & $\begin{array}{l}\text { 14. Comparing the policeman with camera device, cameras deter the drivers with traffic laws more } \\
\text { than policemen? }\end{array}$ & 54.1 & 26 & 19.9 \\
\hline & 15. Do you think that policemen can be replaced by camera devices? & 32.4 & 51.7 & 15.9 \\
\hline
\end{tabular}

locations, 56.1\% indicated that the AEP affect their behaviour at similar locations with no cameras. $72.1 \%$ of them stated that the AEP discourage them from braking traffic laws. Also, 76.9\% think that the behaviour of other drivers is affected by the AEP.

Drivers were also asked about AEP effect on safety; it was found that only $12.8 \%$ were involved in a crash at the camera location.

When the AEP acceptance was evaluated, $44.4 \%$ of drivers think that the AEP satisfy its objective in enhancing traffic safety and $52 \%$ of drivers encourage increasing number of camera devices in Amman.

Finally, when comparing the policeman with camera device, $54.1 \%$ of participant stated that cameras deter the drivers from breaking traffic laws more than policemen and $32.4 \%$ of them favour cameras than policemen.

\section{Conclusion}

This study adds to the evidence that excessive speed cameras and red light running cameras can enhance road safety at arterial roads and signalized intersections.

\section{References}

Al Jassar, H., Ali, A. (2004). On the Effect of Enforcement on Road Safety and Driver Behavior in Kuwait. In: Transportation Research Board: $83^{\text {rd }}$ Annual Meeting of Transportation Research Board, Washington, DC, January 2004.

Allsop, R. (2010). The effectiveness of speed cameras. A review of evidence. RAC Foundation, London.

Chinnock, P. (2005). Road Safety Campaigns: Do they work?. Injury Prevention. 11(3), p. 151.

https://doi.org/10.1136/ip.2005.008995
Dangerous Roads Organization. (n.d.). Saudi Arabia has the Highest Road Accident Death Toll in the World. [Online]. Available from: https://www. greenprophet.com/2010/03/saudi-arabia-death-toll-driving/ [Accessed: 4th January 2017].

Decina, L. E., Thomas, L., Srinivasen, R., Staplin, L. (2007). Automated Enforcement: A compendium of Worldwide Evaluations of Results (Report no. DOS HS-810-763). National Highway Traffic Safety Administration, Washington, DC.

Department of Statistics, DOS (2015). [Online]. Available from: http://www. dos.gov.jo/dos_home_a/main/index.htm [Accessed: 1st January 2017]

Gains, A., Heydecker, B., Shrewsbury, J., Robertson, S. (2004). The National Safety Camera Programme: Three-Year Evaluation Report. PA Consulting Group, London, UK.

Greater Amman Municipality, GAM (2017). Central Traffic Department reports. Hu, W., McCartt, A. T. (2015) Effects of Automated Speed Enforcement in Montgomery County, Maryland, on vehicle Speeds, Public Opinion and Crashes. Arlington, VA: Insurance Institute for Highway Safety.

ITS International. (n.d.). Study finds speed cameras cut fatal accidents. (2012).. [Online]. Available from: http://www.itsinternational.com/categories/ enforcement/features/study-finds-speed-cameras-cut-fatal-accidents/ [Accessed: 29th January 2017]

Jadaan, K., AL-Hyari, I., Naghawi, H., Ammourah, R., Al Nabulsi, Z. (2013). Traffic Safety in Jordan: Magnitude, Cost and Potential Countermeasures. Journal of Traffic and Logistics Engineering. 1(1), pp. 54-57. https://doi.org/10.12720/jtle.1.1.54-57

Jordan Traffic Institute (JTI) (n.d.) Traffic Accident statistics reports for years 2004-2016. Ministry of Interior, Jordan. [Online]. Available from: http:// www.psd.gov.jo/images/jti/images/411.pdf [Accessed: 6th January 2017].

Lum, K. M., Wong, Y. D. (2003) Impact of Red Light Camera on Violation Characteristics. Journal of Transportation Engineering. 129(6), pp. 648-656.

https://doi.org/10.1061/(ASCE)0733-947X(2003)129:6(648) 
Maccubbin, R. P., Staples, B. L., Salwin, A. E. (2001). Automated Enforcement of Traffic Signals: A Literature Review. Federal Highway Administration, Washington, DC.

Mountain, L., Hirst, W., Maher, M. (2004). Costing Lives or Saving Liver? A Detailed Evaluation of the Impact of Speed Cameras on Safety. Traffic Engineering and Control, Great Britain.

Mullen, D. (2001). The City of Edmonton Red Light Camera Program in Review. City of Edmonton, Alberta, Canada.

National Highway Traffic Safety Administration. (2015). Critical Reasons for Crashes Investigated in the National Motor Vehicle Crash Causation Survey. Report no. DOT HS 812 115. Washington, DC: National Highway Traffic Safety Administration.

Perez, K., Mari-Dell'Olmo, M., Tobias, A., Borrell, C. (2007). Reducing Road Traffic Injuries: Effectiveness of Speed Cameras in an Urban Setting. American Journal of Public Health. 97(9), pp. 1632-1637.

https://doi.org/10.2105/AJPH.2006.093195
Retting, R. A., Kyrychenko, S. Y. (2002). Reductions in Injury Crashes Associated with Red Light Camera Enforcement in Oxnard, California. American Journal of Public Health. 92(11), pp. 1822-1825.

Ruby, D. E., Hobeika, A. G. (2003) Assessment of Red Light Running Cameras in Fairfax County, Virginia. In: Proceedings of the Transportation Research Board 82nd Annual Meeting. Washington, DC.

Walden, T. D. (2011). Evaluation of Photographic Traffic Signal Enforcement System in Texas, Crash Analysis Program, Center for Transportation Safety, Texas Transportation Institute, Texas A \& M University System. Wilson, C., Willis, C., Hendrikz, J.K., Le Brocque, R., Bellamy, N. (2010). Speed Cameras for the Prevention of Road Traffic Injuries and Deaths. The Cochrane Library 2010, 10. The Cohrane Collaboration, Oxfordshire, England. 